\title{
Telephoned head injury referrals: the need to improve the quality of information provided
}

\author{
K. A. WALTERS
}

Department of Neurosurgery, Pinderfields Hospital, Wakefield WF1 4DG

\section{SUMMARY}

The decision to transfer a patient with a head injury to a neurosurgical department is usually made during a referral telephone call. The referring doctor describes the patient's condition to the neurosurgeon who then decides whether or not the patient needs to be transferred. Failure to inform the neurosurgeon adequately, may result in a disastrous decision to transfer an unstable patient. Alternatively, a patient who needs urgent neurosurgical care may not be transferred. This study assessed the information volunteered by 50 doctors referring head-injured patients. Extra information obtained on request was recorded separately. The referring doctor often failed to provide important information. For example, only 17 doctors volunteered the pulse rate, 16 the blood pressure and six the respiratory rate. Furthermore, the Glasgow Coma Scale was under-used and apparently not understood properly. This may hinder the decision to transfer a patient. A standard referral data sheet is recommended.

\section{INTRODUCTION}

Every year in Great Britain more than 8000 head-injured patients are referred to neurosurgical centres. The Advanced Trauma Life Support course (ATLS) has been approved by the Royal College of Surgeons of England. The course manual (American College of Surgeons, 1989) suggests that the referring and receiving doctors share the responsibility for the patient's transfer. The two doctors should discuss the patient's condition and a management plan should be formulated depending on the patient's needs.

Failure to stabilize the patient before transfer results in an increased risk of death (Gentleman \& Jennett, 1981). To make a wise decision to transfer, certain 
information is required, which includes the vital signs and a description of the degree of coma. The Glasgow Coma Scale (Jennett \& Teasdale, 1974) was formulated to simplify 'consultations between general and special units in cases of recen brain damage'. However, neurosurgeons who accept telephone referrals still find that it is difficult to form a clear picture of the patient's condition. This study was carried out to find out how frequently important information was missing and t£ examine the use and understanding of aspects of the Glasgow Coma Scale.

\section{SUBJECTS AND METHODS}

This study concerns 50 doctors who referred patients by telephone to one of tw\& registrars (who received all referrals) at Pinderfields Hospital from September 1990 until March 1991. The cases were taken from 140 consecutive referrals and the firs $\mathrm{E}$ referral of each doctor was included in the study. The calling doctor was onlyio included in the study once as this was primarily a study of the presentation of information by doctors and not a study of the patients. After basic details were obtained, the doctor was asked to give the patient's history. Volunteered information was recorded using the format in Table 1. The calling doctor's own phrases wer used. When the referring doctor had finished speaking they were asked to supply

Table 1. Telephone referral checklist for head injury (used to collect data for the study)

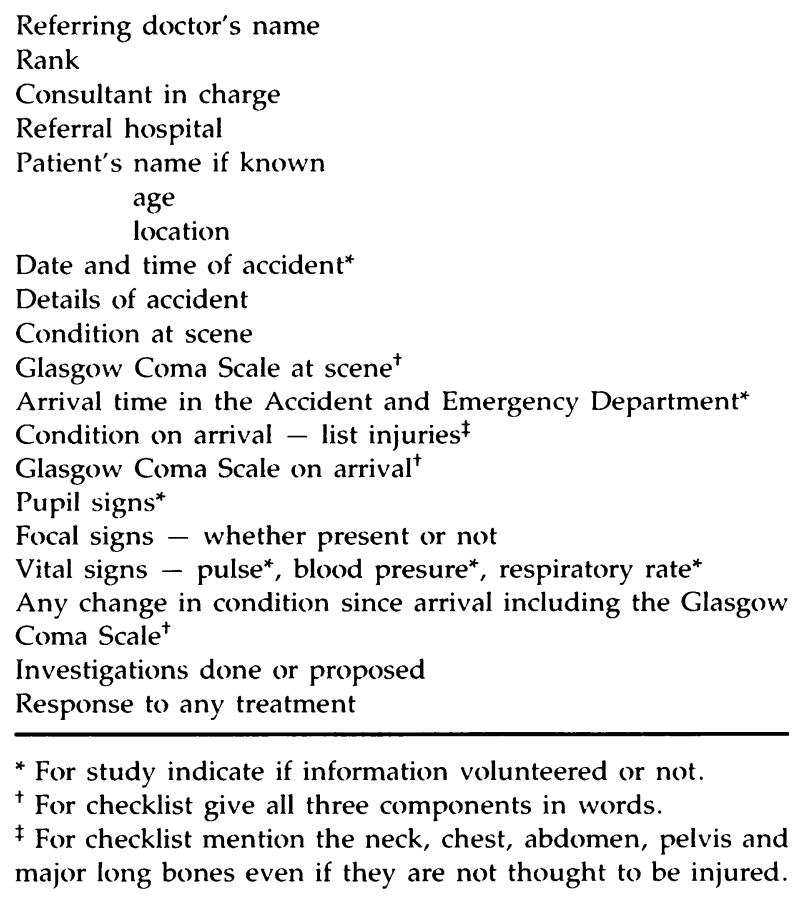

* For study indicate if information volunteered or not.

+ For checklist give all three components in words.

₹ For checklist mention the neck, chest, abdomen, pelvis and major long bones even if they are not thought to be injured. 
essential but missing information or to clarify details. Any information obtained on request was recorded separately.

The doctor was then asked to participate in a study. This was the first time they were aware that information was being recorded. Questions were limited to prevent delays in management of the patient. They were asked the following two questions about the Glasgow Coma Scale: (1) What are the correct stimuli to use when assessing the motor response to pain?; and (2) What is the definition of a localising response to pain? Further explanation was given if necessary.

The calling doctor was thanked for his help and given advice about the patient's management.

\section{RESULTS}

Fifty doctors participated in the study: A\&E, 24 (20 senior house officers, no registrars and four senior ranks); surgical specialties, 24 (one house officer, nine senior house officers, 10 registrars and four senior ranks); paediatrics, two (one senior house officer and one registrar).

Forty-three of the referrals were made less than $24 \mathrm{~h}$ after arrival in the A\&E Department. The availability of the time of the accident, arrival time in the A\&E department, the pupil signs and the vital signs are recorded in Table 2.

Table 3 records whether or not the details of the accident were adequate. Details of the accident were considered adequate if the description given allowed an assessment of the types of injury to expect. For example, 'RTA' was considered inadequate; 'front seat passenger in a crash on the motorway - had to be cut out the driver was killed' was adequate.

Table 3 also records whether or not the Glasgow Coma Scale of the patient at the scene of the accident and in the accident department was available and whether focal signs were mentioned. Patients with no response to pain were presumed to have the minimum Glasgow Coma Scale rating of three.

Table 2. Availability of time of accident, arrival time in A\&E, pupil signs and vital signs

\begin{tabular}{lrrr}
\hline & & No of doctors $(n=50)$ & $\begin{array}{c}\text { Not } \\
\text { available }\end{array}$ \\
\cline { 2 - 4 } & Volunteered & Requested & - \\
\hline Time of accident: & & & - \\
$\quad$ Exact time & 12 & 11 & 17 \\
$\quad$ T' hours/minutes ago & 6 & 4 & 2 \\
Arrival time in A\&E or & 18 & 38 & 1 \\
time of first assessment & 10 & 39 & 4 \\
Pupil signs & 10 & 29 & 5 \\
Pulse rate & 17 & 29 & 22 \\
Blood pressure & 16 & 22 & \\
Respiratory rate & 6 & & \\
\hline
\end{tabular}


Table 3. Availability of further details

\begin{tabular}{|c|c|}
\hline & $\begin{array}{l}\text { No of doctors } \\
\quad(n=50)\end{array}$ \\
\hline \multicolumn{2}{|l|}{ Details of accident: } \\
\hline not available & 3 \\
\hline inadequate ${ }^{*}$ & 3 \\
\hline adequate* $^{*}$ & 41 \\
\hline no witness & 3 \\
\hline \multicolumn{2}{|c|}{ Conscious level at the scene of the accident: } \\
\hline Glasgow Coma Scale (GCS) used & 0 \\
\hline other descriptions & 37 \\
\hline 'no pain response' & 2 \\
\hline \multicolumn{2}{|l|}{ Conscious level in A\&E: } \\
\hline GCS used & 9 \\
\hline 'no pain response' & 2 \\
\hline 'GCS full'/number given & 6 \\
\hline Alternative coma scale & 1 \\
\hline GCS on request & 20 \\
\hline no GCS on request & 12 \\
\hline \multicolumn{2}{|l|}{ Focal signs: } \\
\hline present & 5 \\
\hline not present & 7 \\
\hline description implying no focal signs & 9 \\
\hline 'no pain response' & 2 \\
\hline no comment & 27 \\
\hline
\end{tabular}

* see text for definition.

Patients who had not lost consciousness were assumed to be fully conscious but only one doctor said that the patient was orientated after the accident. Eig patients were reported to be improving soon after losing consciousness but ne Glasgow Coma Scale assessment was available for comparison later.

Those doctors who initially did not use the Glasgow Coma Scale, often used terms such as 'unconscious', 'deeply unconsious', or 'semiconscious'. These terms lacked the precision of the Glasgow Coma Scale but did partly suggest the patiento' condition. Also difficult to interpret were phrases such as 'responds (purposefully to pain', 'moves all four limbs' and 'asleep, responds to mental and physical stimulis.

Not one component of the Glasgow Coma Scale was used to describe eig children aged between 10 weeks and 10 years. Eight entirely separate phrase were used. To illustrate, a 5-year-old child was described as 'unconscious . surfacing intermittently ... tooth grinding ... spat out the airway'.

The answers to the Glasgow Coma Scale questions are in Table 4. Jennett Teasdale (1981) recommended that when testing the motor response to pain, on supra-orbital nerve pressure and nail bed pressure should be used. Also, a localizin response to pain was recorded if the hand moves above the chin towards the supra-orbital stimulus'. The original definition (Jennett \& Teasdale, 1974) was less specific and said 'a localizing response indicates that a stimulus at more than or site causes a limb to move so as to attempt to remove it'. 
Table 4. Answers to Glasgow Coma Scale questions

\begin{tabular}{lc}
\hline & No of doctors $(n=50)$ \\
\hline $\begin{array}{l}\text { Method of pain production } \\
\text { testing the motor response: }\end{array}$ \\
pressure on nail bed & 21 \\
pressure on supraorbital nerve & 13 \\
other methods* & 33 \\
did not know & 12 \\
exact 1981 definition & 2 \\
1981 definition + extra & 5 \\
Definition of the localising & \\
response to pain: & 0 \\
1981 definition & 21 \\
hand moved toward stimulus & \\
(similar to 1974 definition) & 29 \\
did not know & \\
\hline * Included pinching ear lobes, rubbing the sternum and \\
squeezing testicles.
\end{tabular}

squeezing testicles.

\section{DISCUSSION}

This study has shown that many doctors fail to volunteer important information when referring head-injured patients by telephone. When asked for missing information it was either not available or there was a delay while it was obtained.

The details of the accident are important as they give a guide to the risk of intracranial haematoma or multiple injury (Gentleman et al., 1986). If a severely headinjured patient arrives at a neurosurgical centre hypoxic and hypotensive, their risk of death is high (Gentleman \& Jennett, 1981). To prevent a disastrous decision to transfer a patient, the neurosurgeon must know the patient's vital signs.

It is important to find out the condition of the patient soon after the accident; whether the patient talked afterwards and whether the patient is stable, improving or deteriorating (Jennett \& Teasdale, 1981). The time of assessments is vital. The rate of deterioration can be assessed properly only if the degree of coma is known at different times.

Undefined descriptive terms can be useful but it is sensible for everyone to use a well known method of assessing the level of consciousness. The Glasgow Coma Scale (Jennett \& Teasdale, 1974, 1981) is widely known. It was designed to simplify consultations about cases of recent brain damage. It was originally thought to be reliable when used by people of all grades of experience (Teasdale et al., 1978) but this has now been questioned (Rowley \& Fielding, 1991). To ensure reliability and accuracy, especially when comparing assessments, it is essential that everyone using the Glasgow Coma Scale is taught to use the same version. The 1981 definitions (Jennett \& Teasdale, 1981) should be used as they improve on the techniques of 1974. When examining children the paediatric version of the Glasgow Coma Scale described in the ATLS Course manual could be used (American College of Surgeons, 1989, pp. 226). 
The prognosis of head-injured patients is improved with prompt treatment (Seelig et al., 1981). Secondary brain injury must be avoided. Guide-lines of details to check have been published (Gentleman \& Jennett, 1990). If neurosurgical help is? required then a clear report about the patient must be given to the neurosurgeon $\overrightarrow{\vec{v}}$ Table 1 gives an outline of the information that should be available when the neurosurgeon is contacted. The flow of information during the telephone conver sation would then be concise and precise, hopefully to the greater benefit of the patient.

\section{REFERENCES}

Advanced Trauma Life Support Student Manual. (1989) American College of Surgeons, Chigago, Illinois Gentleman D. \& Jennett B. (1981) Hazards of interhospital transfer of comatose head-injured patients Lancet ii, 853-5.

Gentleman D. \& Jennett B. (1990) Audit of transfer of unconscious head-injured patients to a neuro surgical unit. Lancet 335, 330-34.

Gentleman D., Teasdale G. \& Murray L. (1986) Cause of severe head injury and risk of complications British Medical Journal 292, 449.

Jennett B. \& Teasdale G. (1974) Assessment of coma and impaired consciousness. Lancet ii, 81-4. Jennett B. \& Teasdale G. (1981) Management of head injuries, pp. 78, 96-98. F. A. Davis Company,

Philadelphia.
Rowley G. \& Fielding K. (1991) Reliability and accuracy of the Glasgow Coma Scale with experienged and inexperienced users. Lancet 337, 535-38.

Seelig J. M., Becker D. P., Miller J. D., Greenberg R. P., Ward J. D. \& Choi S. C. (1981) Traumatic acưt subdural haematoma: Major mortality reduction in comatose patients treated within four hoursō Neze England Journal of Medicine 304, 1511-18.

Teasdale G., Knill-Jones R. \& Vande der Sande J. (1978) Observer variability in assessing impaire $\mathbb{B}$ consciousness and coma. Journal of Neurology, Neurosurgery and Psychiatry 41, 603-10. 